\title{
Characterisation of Carbon Nano Tube Reinforced with hemp/vinyl Ester/Carbon Fiber Laminated Hybrid Composite
}

\author{
Nandini MC"1, Dr. Shivarudraiah ${ }^{2}$, Dr. H K Shivanand2, Puneeth $\mathrm{P}^{3}$
}

${ }^{* 1}$ Research Scholar, Mechanical Engineering, University Visvesvaraya College of Engineering, Bangalore, Karnataka, India ${ }^{2}$ Professor, Mechanical Engineering, University Visvesvaraya College of Engineering, Bangalore, Karnataka, India ${ }^{3}$ PG Scholar, Mechanical Engineering, University Visvesvaraya College of Engineering, Bangalore, Karnataka, India

\begin{abstract}
Article Info
Volume 8, Issue 5

Page Number : 21-28
\end{abstract}

\section{Publication Issue}

September-October-2021

\section{Article History}

Accepted : 05 Sep 2021

Published : 14 Sep 2021

\section{ABSTRACT}

In Recent days, the natural fibres from renewable natural resources offer the potential to act as a reinforcing material for polymer composites alternative to the use of glass, carbon and other man-made fibres. Among various fibres, Hemp is most widely used natural fibre due to its advantages like easy availability, low density, low production cost and satisfactory mechanical properties. Composite materials play a vital role in the field of materials to meet the stringent demands of light weight, high strength, corrosion resistance and near-net shapes. Composite is a structural material that consists of two or more combined constituents that are combined at a macroscopic level and are not soluble in each other. Composites are having two phases that are reinforcing phase like fiber, particle, or flakes \& matrix phase like polymers, metals, and ceramics.In this project an attempt is made to prepare different combination of composite materials using hemp/carbon fiber and Carbon nano tube reinforcement and vinyl ester as the matrix material respectively. Composites were prepared according to ASTM standards and following test are carried out Density test, Water absorption test and Impact test.The effect of addition of Carbon nano tubes in hemp/vinyl ester/carbon fibers has been studied \& it has been observed that there is a significant effect of fibre loading and performance of hemp/carbon fiber reinforced vinyl ester based hybrid composites with improved results.

Keywords: Hemp Fiber, Vinyl Ester, Carbon Fiber, Density Test, Water Absorption Test And Impact Test.

\section{INTRODUCTION}

The development of composite materials and their related design and manufacturing technologies is one of the most important advances in the history of materials. Composites are the material used in various fields having exclusive mechanical and physical properties and are developed for particular application. Composite materials having a range of advantages over other conventional materials such 
as tensile strength, impact strength, flexural strengths, stiffness and fatigue characteristics. Because of their numerous advantages they are widely used in the aerospace industry, commercial mechanical engineering applications, like machine components, automobiles, combustion engines, mechanical components like drive shafts, tanks, brakes, pressure vessels and flywheels, thermal control and electronic packaging, railway coaches and aircraft structures etc.

When two or more materials with different properties are combined together, they form a composite material. Composite material comprise of strong load carrying material (known as reinforcement) imbedded with weaker materials (known as matrix).The primary functions of the matrix are to transfer stresses between the reinforcing fibres/particles and to protect them from mechanical and/or environmental damage whereas the presence of fibres/particles in a composite improves its mechanical properties like tensile strength, flexural strength, impact strength, stiffness etc.

Composites can be classified according to different criteria. Depending on the type of matrix materials, composite materials can be classified into three categories such as metal matrix composites, ceramic matrix composites and polymer matrix composites. Each type of composite material is suitable for specific applications. When the matrix material is taken as metal like aluminum, copper, it is called as metal matrix composite. These are having high ductility and strength, good fracture toughness, inter-laminar shear strength and transverse tensile strength and also having superior electrical and thermal conductivity. These materials are high dimensional stable due to low thermal expansion coefficient of matrix and withstand to a high temperature. Due to high elastic modulus of reinforcements they have very high stiffness. When the matrix material is taken as ceramic it is called as ceramic matrix composite. Ceramic material include a wide verity of inorganic materials likes bricks, pottery, titles also include oxide, nitrides and carbides of silicon, aluminum, zirconium etc. They are normally non metallic and processed very often at high temperature. The main objective in producing ceramic matrix composites is to enhance the toughness, high strength and hardness, high temperature properties, wear resistance etc.

Polymer matrix composites consist of a polymer resin as the matrix material which filled with a variety of reinforcements. This kind of composite is used in the greatest diversity of composite applications due to its advantages such as low density, good thermal and electrical insulator, ease of fabrication, and low cost. The properties of polymer matrix composites are mainly determined by three constitutive elements such as the types of reinforcements (particles and fibres), the type of polymer, and the interface between them. Polymers are divided into two categories such as thermoplastics and thermosets. Thermoplastic are in general, ductile and tougher than thermoset materials. They are reversible and can be reshaped by application of heat and pressure. Thermoplastic molecules do not cross-link and therefore they are flexible and reformable. Generally, thermoplastics show poor creep resistance, especially at elevated temperatures, as compared to thermosets. Their lower stiffness and strength values require the use of fillers and reinforcements for structural applications. The most common materials used in thermoplastic composites are nylon, polyetheretherketone, Acetal, polyphenylene sulfide, polycarbonate, Teflon, polyethylene etc. Thermoset are materials that undergo a curing process through part fabrication and once cured cannot be re-melted or reformed. Thermoset material are brittle in nature and offer greater dimensional stability, better rigidity, and higher chemical, electrical, and solvent resistance. The most common resin materials used in thermoset composites are epoxy, polyester, phenolics, vinyl ester, and polyamides. 
Based on the types of reinforcement, polymer composites can be classified as particulate reinforced polymer composite and fibre reinforced polymer composites. Particle reinforced composites also called particulate composites consisting of reinforcing material that is in the form particle. The shape of reinforcing particle may either spherical, a platelet, cubic, tetragonal, or of other regular or irregular geometry. The arrangement of the particles in the composites may be either random or preferred orientation. Generally, particles are used in composites to modify the thermal and electrical conductivities, improve performance at elevated temperatures, reduce friction, increase wear and abrasion resistance, improve machinability, increase surface hardness and reduce shrinkage.

Fibre reinforced polymer composites also called fibrous composites consisting of fibres as the reinforcement. Now-a-days, these composites have found applications in various areas such as automotive, marine, aerospace etc. due to their high specific stiffness and strength. Generally, fibres are the most important class of reinforcements in composite materials, as they satisfy the desired conditions and transfer strength to the matrix constituent, influencing and enhancing their desired properties. A fibre is characterized by its length being much greater as compared to its cross-sectional dimensions. The properties of matrix, fibre and its interface have greatly influencing the properties of composite materials.

Fibres in polymer composites can either synthetic/man-made fibres or natural fibres. Some commonly used synthetic fibres for composites are glass, aramide and carbon etc.

Among various natural plant fibres, Over hundreds of years Jute/Hemp has been used in the applications of ropes, beds, bags etc. Jute is abundantly available in countries like India, Bangladesh, China, Nepal and Thailand. It possesses high toughness and aspect ratio in comparison to other natural fibres. Hemp is a lingo-cellulosic fibre and its composites have high impact strength with moderate tensile and flexural properties compared to other fibres like coir, sisal, pineapple, banana etc.

\section{EXPERIMENTATION}

\section{A. Materials}

Reinforcements are selected and their composites are considered based on the previous work done by the researchers. The following materials are used in this project and same as been discussed below.

1. Hemp fiber : Hemp or industrial hemp typically found in the northern hemisphere, is a variety of the Cannabis saliva plant species that is grown specifically for the industrial uses of its derived products. It is one of the fastest growing plants and was one of the first plants to be spun into usable fiber 10,000 years ago. It can be refined into a variety of commercial items including paper, textiles, clothing, biodegradable plastics, paint, insulation, biofuel, food, and animal feed.

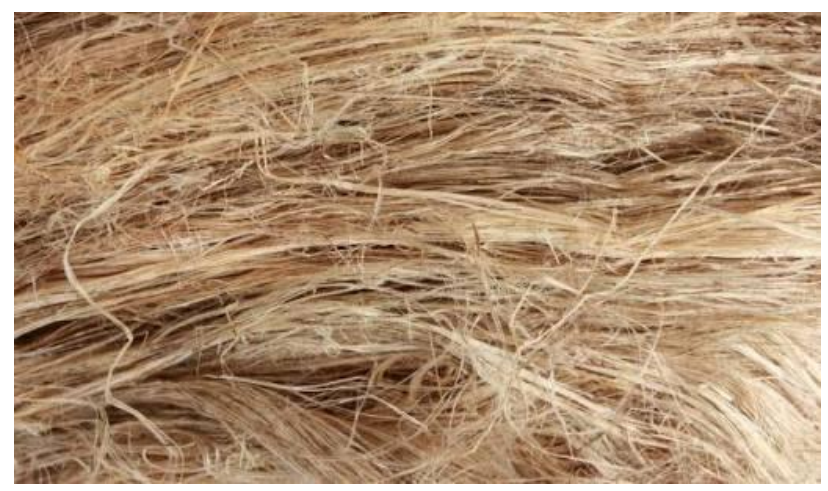

Fig 2.1: Hemp fibers.

2. Carbon fiber : Carbon fibers are known for its high performance and durability and hi-tech applications, carbon fibers possesses best-in-class properties in fibrous reinforcements enabling it to meet the most desirable parameter of high strength to density ratio in composites. Carbon fibers being 
very strong and stiff, can withstand the higher temperatures up to $23000 \mathrm{C}$. Their excellent dimensional stability enabled the carbon fibers obvious choice in applications related to space, aeronautics, defence and military, automobiles etc. Carbon fibers are often known as the hi-tech fibers and composites made up of carbon fibers are termed as classy materials.

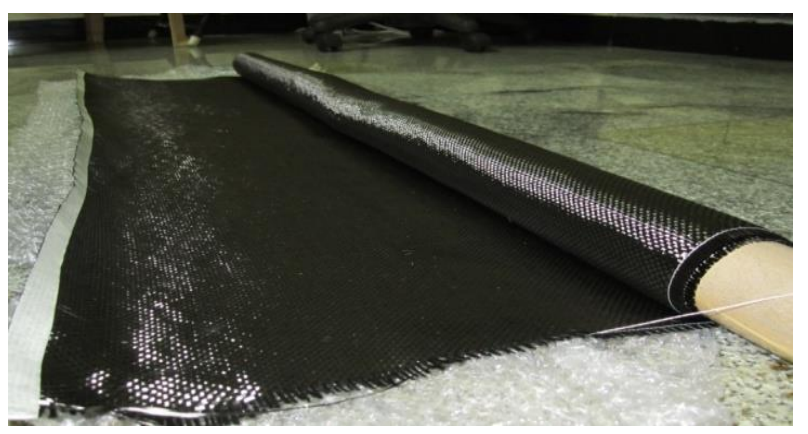

Fig 2.2: Carbon fibers.

3. Carbon Nanotubes: CNTs are tubular forms of carbon that can be visualized as a sheet of graphite rolled into cylindrical form. There are two basic types of CNTs: single-walled carbon nanotubes (SWCNTs) and multi-walled carbon nanotubes (MWCNTs).

\section{Properties of CNTs :}

- Carbon nanotubes are among the strongest and stiffest materials, with Young's moduli as high as over 1TPa.

- Tensile strengths of up to $200 \mathrm{GPa}$, which is several hundred times more than that of steel. Besides,

- CNTs can suffer up to $15 \%$ strain before fracture as the elastic response to deformation.

- Excellent electrical properties as conductors with a high electrical conductivity (even $>103 \mathrm{~S} / \mathrm{cm}$ ). In addition,

- CNTs are thermally stable up to $2800^{\circ} \mathrm{C}$ in vacuum.

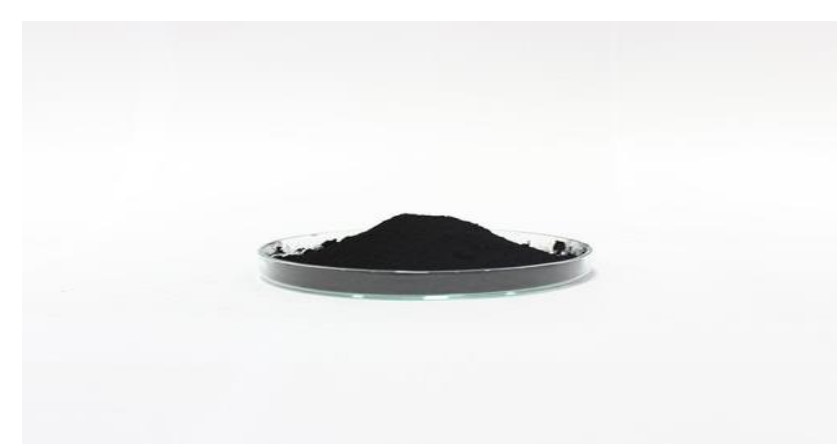

Fig 2.3: Carbon Nanotube.

4. Vinyl Ester Resin: VE resin is an g-backbone based thermoset resin whose curing properties are similar to those of the unsaturated polyester resins. Compared to polyester, VE resins differ primarily in the location of their unsaturated sites, which are reactive groups only at the ends of the molecular chains.

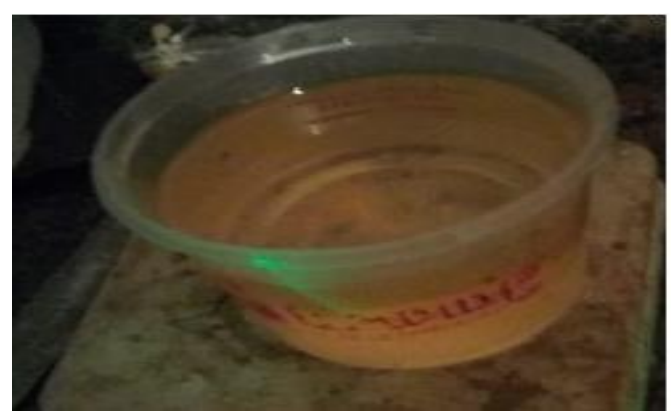

Fig 2.4: Vinyl Ester resin.

\section{B. Fabrication of the specimen.}

Hand layup technique: Hand lay-up technique is the simplest method of composite processing. The infrastructural requirement for this method is also minimal. The processing steps are quite simple.

Resins are impregnated by hand into fibres which are in the form of woven, knitted, stitched or bonded fabrics. This is usually accomplished by rollers or brushes, with an increasing use of niproller type impregnators for forcing resin into the fabrics by means of rotating rollers and a bath of resin. Laminates are left to cure under standard atmospheric conditions. 


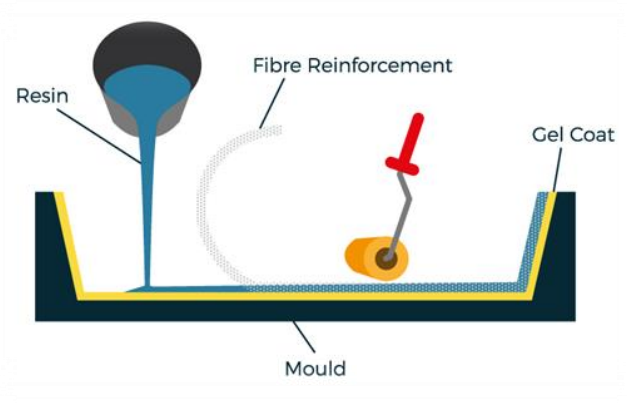

Fig 2.5: Hand layup technique.

\section{Composition of the specimen}

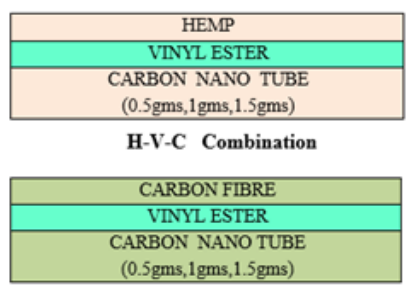

C-V-C Combination

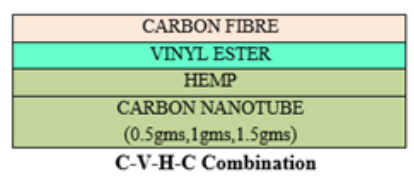

Fig 2.6 : Combination of fibers.

\section{TESTING OF COMPOSITES}

\section{Density Test:}

The density test of hybrid nano composites are performed on laminates as per the ASTM standard D2734-35 while answers are presented in the table.

\begin{tabular}{|c|c|c|}
\hline \multicolumn{3}{|c|}{ HVC combination } \\
\hline Sl.No & SAMPLE (H-V-C) & Density \\
\hline 1 & CNT $(0.25 \%)$ & 1.08 \\
\hline 2 & CNT $(0.5 \%)$ & 1.105 \\
\hline 3 & CNT $(0.75 \%)$ & 1.07 \\
\hline \multicolumn{3}{|c|}{ CVC combination } \\
\hline Sl.No & SAMPLE (C-V-C) & Density \\
\hline 1 & CNT $(0.25 \%)$ & 1.12 \\
\hline 2 & CNT $(0.5 \%)$ & 1.14 \\
\hline 3 & CNT $(0.75 \%)$ & 1.14 \\
\hline \multicolumn{3}{|c|}{ CVH combination } \\
\hline Sl.No & SAMPLE (C-V-H) & Density \\
\hline 1 & CNT (0.25\%) & 1.105 \\
\hline 2 & CNT (0.5\%) & 1.11 \\
\hline
\end{tabular}

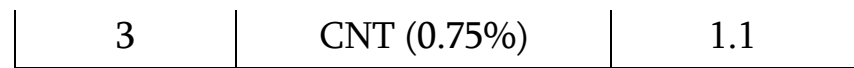

Table 3.1: Density test results

\section{Density \\ CVC Combination}

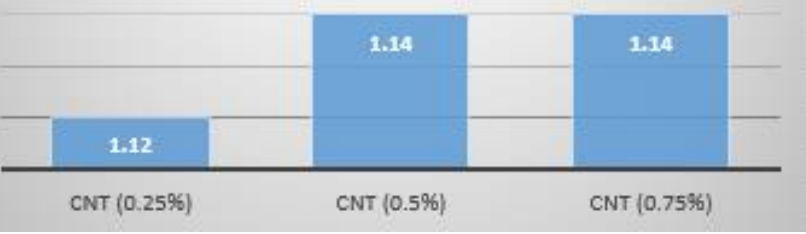

Fig 3.1: Density test results of CVC combination

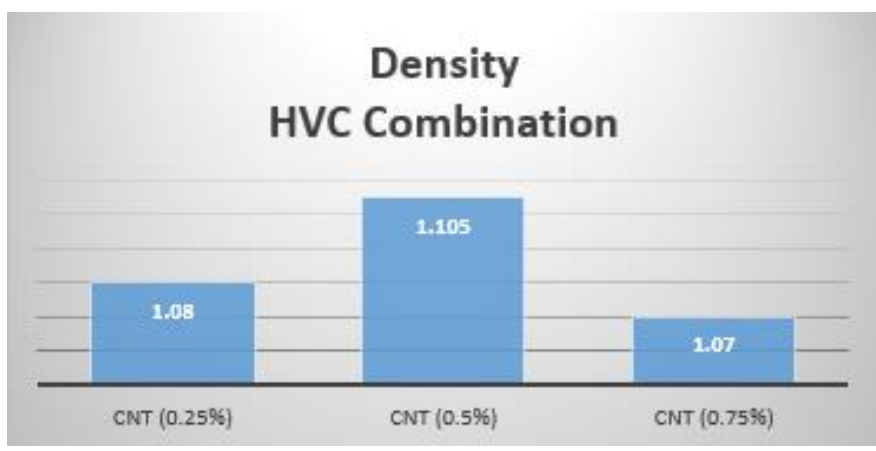

Fig 3.2: Density test results of HVC combination

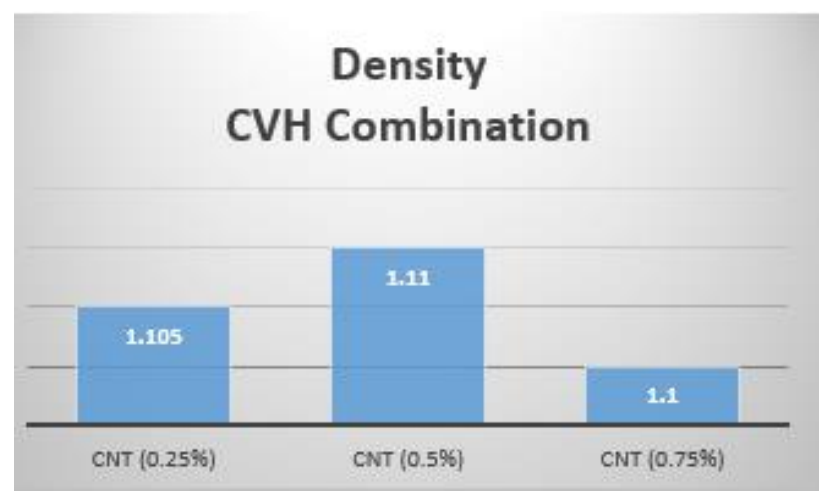

Fig 3.3: Density test results of CVH combination.

\section{Water absorption Test}

Water absorption test is carried out to obtain the required quality of a composite specimen and moisture absorption test is a gravimetric test method that monitors change over time of moisture content 
by measuring the total mass change of a specimen that is exposed to a specified environment. The samples used for water absorption test is ASTM D5229 of (100x100x4mm3).

\begin{tabular}{|c|c|c|}
\hline \multicolumn{3}{|c|}{ HVC combination } \\
\hline Sl.No & $\begin{array}{c}\text { SAMPLE (H-V- } \\
\text { C) }\end{array}$ & $\begin{array}{c}\text { Water absorption in } \\
\text { Percentage }\end{array}$ \\
\hline 1 & CNT $(0.25 \%)$ & 1.2 \\
\hline 2 & CNT $(0.5 \%)$ & 1.58 \\
\hline 3 & CNT (0.75\%) & 1.885 \\
\hline \multicolumn{3}{|c|}{ CVC combination } \\
\hline Sl.No & $\begin{array}{c}\text { SAMPLE (C-V- } \\
\text { C) }\end{array}$ & $\begin{array}{c}\text { Water absorption in } \\
\text { Percentage }\end{array}$ \\
\hline 1 & CNT (0.25\%) & 0.05 \\
\hline 2 & CNT $(0.5 \%)$ & 0.11 \\
\hline 3 & CNT (0.75\%) & 0.11 \\
\hline \multicolumn{3}{|c|}{ CVH combination } \\
\hline Sl.No & $\begin{array}{c}\text { SAMPLE (C-V- } \\
\mathrm{H})\end{array}$ & $\begin{array}{c}\text { Water absorption in } \\
\text { Percentage }\end{array}$ \\
\hline 1 & CNT (0.25\%) & 0.895 \\
\hline 2 & CNT (0.5\%) & 0.79 \\
\hline 3 & CNT (0.75\%) & 0.51 \\
\hline
\end{tabular}

Table 3.2: Moisture absorption test results.

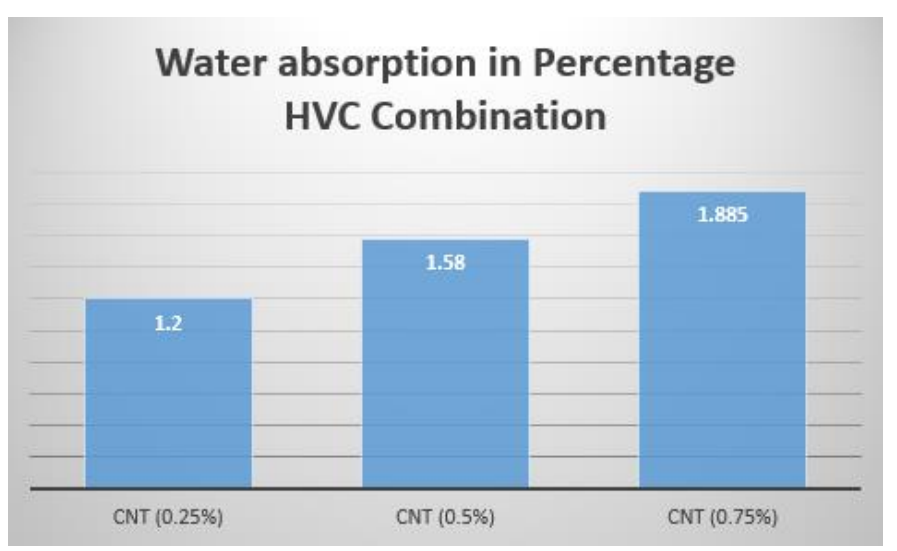

Fig 3.4: Water absorption test results of CVH combination.

\section{Water absorption in Percentage CVC Combination}



Fig 3.5: Water absorption test results of CVH combination.



Fig 3.6: Water absorption test results of $\mathrm{CVH}$ combination.

\section{Impact Test}

The density test of hybrid nano composites are performed on laminates as per the ASTM standard while answers are presented in the table.

\begin{tabular}{|c|c|c|}
\hline \multicolumn{3}{|c|}{ HVC combination } \\
\hline Sl.No & SAMPLE (H-V-C) & Impact Strength \\
\hline 1 & CNT $(0.25 \%)$ & 2 \\
\hline 2 & CNT $(0.5 \%)$ & 2.5 \\
\hline 3 & CNT $(0.75 \%)$ & 2.5 \\
\hline \multicolumn{3}{|c|}{ CVC combination } \\
\hline Sl.No & SAMPLE (C-V-C) & Impact Strength \\
\hline 1 & CNT $(0.25 \%)$ & 2.5 \\
\hline 2 & CNT $(0.5 \%)$ & 2.5 \\
\hline 3 & CNT $(0.75 \%)$ & 2 \\
\hline
\end{tabular}




\begin{tabular}{|c|c|c|}
\hline \multicolumn{3}{|c|}{ CVH combination } \\
\hline Sl.No & SAMPLE (C-V-H) & Impact Strength \\
\hline 1 & CNT $(0.25 \%)$ & 2.5 \\
\hline 2 & CNT $(0.5 \%)$ & 2.5 \\
\hline 3 & CNT $(0.75 \%)$ & 2 \\
\hline
\end{tabular}

Table: 3.3: Impact Test Results

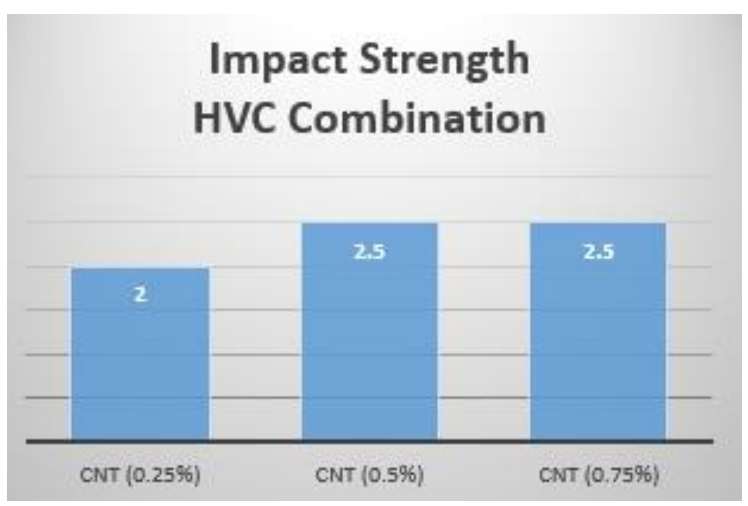

Fig 3.7: Impact test results of CVH combination

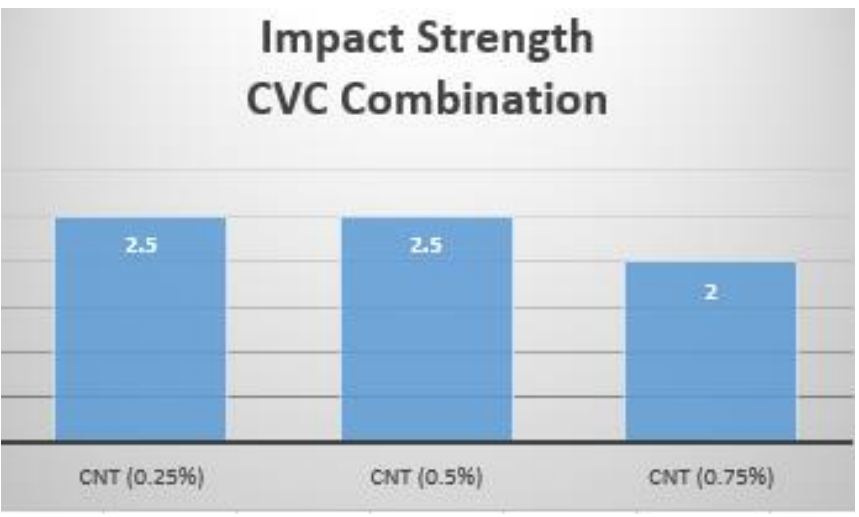

Fig 3.8: Impact test results of CVC combination

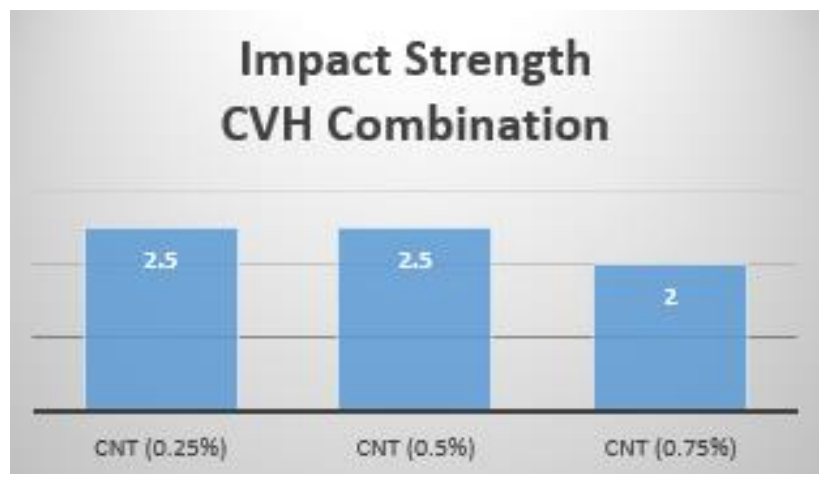

Fig 3.9: Impact test results of HVC combination

\section{CONCLUSION}

This investigation of Hemp/Carbon fiber and Carbon nano tubes reinforced composites leads to following significant conclusions.

- The incorporation of carbon nanotubes into the Vinyl Ester fibers shows the mechanical properties almost enhanced to greater extent.

- It is observed that the addition of carbon nano tube greatly influences on Hemp/Carbon fiber composite strengths.

- This work shows successful fabrication of a new class of Vinyl Ester based hybrid composites reinforced with Hemp/Carbon fiber is possible.

- A simple hand lay-up technique is adopted to fabricate successfully Hemp/Carbon fiber fibers with different proportions of CNT reinforcement are observed.

- The addition CNT of weight percentage in all three combination showed that $0.25 \% \mathrm{CNT}$ is increased its impact strength than compared to $0.5 \%$ and $0.75 \%$ of CNT.

- It clear that increasing carbon percentage water absorption decreases

\section{REFERENCES}

[1]. WEN-PIN LIN, HSUAN-TEH HU, Parametric Study on the Failure of Fibre-Reinforced Composite Laminates under Biaxial Tensile Load, Journal of composite materials, Vol. 36, No. 12/2002, pp 1481-1503.

[2]. Topdar, A. H. Sheikh and N. Dhang Finite Element Analysis of Composite and Sandwich Plates Using a Continuous Inter-laminar Shear Stress Model P. Journal of Sandwich Structures and Materials 2003; 5; 207.

[3]. Y.Li, K.J.Xian, C.L. Choy, Meili Guo, Zuoguang Zhang; "Compressive and flexural behavior of ultra-high-modulus polyethylene fibre and 
carbon fibre hybrid composites," Comp. Sci. \& Tech., vol.59, 1999, pp. 13-18.

[4]. Georgel Chirita1, Gabriel Andrei1, Iulian Gabriel Birsan1, Dima Dumitru2, Alina Cantaragiu1 ELECTRICAL PROPERTIES CHARACTERIZATION OF VINYL ESTER RESIN FILLED WITH CARBON NANOTUBES e-mail: george.chirita@ugal.ro

[5]. O. Gryshchuk a, J. Karger-Kocsis a, ${ }^{*}$, R. Thomann b, Z. Ko'nya c, I. Kiricsi c Multiwall carbon nanotube modified vinylester and vinylester - based hybrid resins Kaiserslautern, Erwin-Schro" dinger-Str. 58, D-67663 Kaiserslautern, Germany Applied and Environmental Chemistry Department, University of Szeged, Rerrich Be'la te'r $1, \mathrm{H}-$ 6720 Szeged, Hungary Received 4 June 2005; received in revised form 4 September 2005; accepted 4 September 2005

[6]. Memduh KARA, Mesut UYANER As MW-CNT can be treated as a flexible Low velocity impact behavior of carbon nanotube filled glass fiber/vinyl ester composites, Selcuk University, Selcuklu, Konya, Turkey

[7]. Fabrizio Marra Alessandro Giuseppe D'Aloia 1,2, Alessio Tamburrano 1,2,Isabel Maria Ochando 3, Giovanni De Bellis 1,2, Gary Ellis 3 and Maria Sabrina Sarto 1,2, ${ }^{*}$ Electromagnetic and Dynamic Mechanical Properties of Epoxy and Vinylester-Based Composites Filled with Graphene CSIC, 28006 Madrid, Spain; iochando@ictp.csic.es (I.M.O.); gary@ictp.csic.es (G.E.)* Correspondence: mariasabrina.sarto@uniroma1.it; Tel.: +39-064458-5542

[8]. Academic Editor: Ton Peijs Received: 29 May 2016; Accepted: 21 July 2016; Published: 28 July 2016.

[9]. Liao SH, Yen CY, Hung CH, Weng CC, Tsai MC, Lin YF, M. Ma CC, Pan C, Su A. J. Mater. Chem. 18, 3993, 2008.
[10]. Seyhan AT, Gojny FH, Tanoglu M, Schulte K. Eur. Polym. J. 42, 2836, 2007.

[11]. Thostenson ET, Ziaee S, Chou TW. Compos. Sci. Technol. 69, 801, 2009.

[12]. Seyhan AT, Tanoğlu M, Schulte K. Mat. Sci. Eng. A-Struct. 523, 85, 2009.

[13]. Seyhan AT, de la Vega A, Tanoğlu M, Schulte K. J. Polym. Sci. Pol. Phys. 47, 1511, 2009

[14]. Yurdakul H, Seyhan AT, Turan S, Tanoğlu M, Bauhofer W, Schulte K. Compos. Sci. Technol. 70, 2102, 2010.

[15]. Fan ZH, Hsiao KT, Advani SG. Carbon. 42, 871, 2004.

[16]. Bily MA, Kwon YW, Pollak RD. Appl. Compos. Mater. 17, 347, 2009

[17]. Zhu J, Imam A, Crane $\mathrm{R}$, Lozano $\mathrm{K}$, Khabasheku VN, Barrera EV. Comp. Sci. Tech. 67, 1509, 2007.

[18]. P. Karapappas1, S. Tsantzalis1, E. Fiamegou1, A. Vavouliotis1, K. Dassio Multi-Wall Carbon Nanotubes Chemically Grafted and Physically Adsorpted on Reinforcing Carbon Fibres Received 24 January 2008; accepted 19 May 2008

[19]. H.W. Zhou , L. Mishnaevsky Jr. , H.Y. Yi, Y.Q. Liu , X. Hu , A. Warrier , G.M. Dai Carbon fiber/carbon nanotube reinforced hierarchical composites: Effect of CNT distribution on shearing strength KU Leuven, MTM, B-3001 Heverlee, Belgium

\section{Cite this article as :}

Nandini MC, Dr. Shivarudraiah, Dr. H K Shivanand, Puneeth $\mathrm{P}$ "Classification and Performance of Biometric Authentication", International Journal of Scientific Research in Computer Science, Engineering and Information Technology (IJSRCSEIT), ISSN : 2456-3307, Volume 7 Issue 5, pp. 16-20, SeptemberOctober 2021. Available at doi $\quad$ : https://doi.org/10.32628/CSEIT21753 Journal URL : https://ijsrcseit.com/CSEIT21753 